\title{
Predation of Halyomorpha halys (Hemiptera: Pentatomidae) from Web-Building Spiders Associated with Anthropogenic Dwellings
}

\author{
William R. Morrison III ${ }^{1}$ - Alexandria N. Bryant ${ }^{2}$. \\ Brittany Poling ${ }^{3} \cdot$ Nicole F. Quinn $^{4}$. \\ Tracy C. Leskey ${ }^{1}$
}

Revised: 6 January 2017 / Accepted: 11 January 2017 /

Published online: 23 January 2017

(C) Springer Science+Business Media New York (outside the USA) 2017

\begin{abstract}
The brown marmorated stink bug, or Halyomorpha halys, is an invasive pest in North America and Europe that causes severe agricultural damage and nuisance problems for homeowners; and it is originally from China, Taiwan, and the Republic of Korea. While the natural enemy community of $H$. halys has been evaluated in several agroecosystems, it has not been examined where H. halys overwinters in anthropogenic structures. The aims of the current study were to evaluate 1) whether spider webs commonly found in the home and yard can successfully ensnare $H$. halys, 2) whether entanglement resulted in consumption by spiders inhabiting the webs, and 3 ) how frequently $H$. halys becomes entangled in webs under ambient conditions. To accomplish this, adult $H$. halys were introduced into webs in and near anthropogenic structures in West Virginia and Maryland, United States, and the behavior of spiders was observed for 5-min intervals at $0,1,2$, and $24 \mathrm{~h}$ after introduction. In addition, a survey of webs was performed to determine the frequency with which spiders naturally capture $H$. halys inside buildings and in the landscape. Overall, the study found seven spider families in anthropogenic structures. Adult $H$. halys that were introduced into the webs of
\end{abstract}

Electronic supplementary material The online version of this article (doi:10.1007/s10905-017-9599-z) contains supplementary material, which is available to authorized users.

William R. Morrison, III

william.robert.morrison@gmail.com

1 USDA-ARS Appalachian Fruit Research Station, 2217 Wiltshire Rd., Kearneysville, WV 25430, USA

2 Breckinridge County Extension Service, Hardinsburg, KY 40143, USA

3 Department of Biological Sciences, Shepherd University, Shepherdstown, WV 25443, USA

4 Department of Entomology, Virginia Tech, Blacksburg, VA 24061, USA 
Theridiidae, Pholcidae, or Agelenidae had a greater than $50 \%$ chance of being ensnared and consumed. Adult $H$. halys were found naturally most often in webs of Theridiidae. Webs with a funnel or cob web architecture had the greatest probability of ensnaring $H$. halys, while those with orb structures resulted in the fewest caught. In the wild, 13-20\% of spider webs contained dead $H$. halys. Our results suggest that spiders may be an important contributing factor for mortality of $H$. halys at overwintering sites, and spiders in or outside homes may help reduce nuisance problems caused by $H$. halys.

Keywords Biological control b brown marmorated stink bug · natural enemies · nuisance overwintering · urban

Invasive species are a global threat to food production, especially in light of increasing connectivity and commerce. The brown marmorated stink bug, Halyomorpha halys (Stal) (Hemiptera: Pentatomidae), is a widespread invasive species that was introduced to the United States in the mid-1990s (Hoebeke and Carter 2003; Leskey et al. 2012a). In 2010 , it was estimated to have caused $\$ 37$ million in damage to apple alone, and in some cases insecticide use has increased up to four-fold since that point (Leskey et al. 2012c). In addition, it feeds on over 100 host plants, many of them economically important crops (Rice et al. 2014). Since then, it has also been found in Europe (Wermelinger et al. 2008), Canada (Fogain and Graff 2011), intercepted in New Zealand (Lee 2015), and is projected to spread even further (Haye et al. 2015b; Zhu et al. 2012). Several advances have been made including characterizing the feeding damage caused by $H$. halys (e.g. Nielsen and Hamilton 2009a; Owens et al. 2013; Wiman et al. 2015), characterizing the H. halys aggregation pheromone and synergist (Khrimian et al. 2014; Weber et al. 2014), as well as developing reliable monitoring tools (Leskey et al. 2015a, 2015b; Leskey et al. 2012b; Morrison et al. 2015). Increasingly, the focus of research in the United States has turned to management of this invasive species (Blaauw et al. 2014; Morrison et al. 2016a; Soergel et al. 2015; Nielsen et al. 2016a), including on biological control (Morrison et al. 2016b; Lara et al. 2016).

In managing $H$. halys, the phenology of the pest needs to be considered. The species emerges from overwintering sites in early spring from April to early June where a combination of both photoperiod and temperature cues trigger dispersal (Lee et al. 2013; Nielsen et al. 2016b). During the summer, adults frequently switch from crop to crop, feeding on fruits as they mature (Martinson et al. 2015). For example, H. halys may switch from peaches after they are harvested to apples and then to soybeans in the late fall. The species is bivoltine (two generations per year) in more southerly points of the mid-Atlantic (Leskey et al. 2012b), but only univoltine (one generation per year) at latitudes farther north (Nielsen and Hamilton 2009b). Peak populations for H. halys adults are reached in the late season between late August and early September. Around the autumnal equinox, adults start seeking out overwintering sites in natural areas with dead, standing trees (Lee et al. 2014), or unheated or heated sheds, homes, and other anthropogenic structures where it is a major nuisance pest (Inkley 2012).

Halyomorpha halys is vulnerable to natural enemies in the summer when the pest can primarily be found in agroecosystems and wild host refugia (Nielsen and Hamilton 2009a). The natural enemy community of $H$. halys in agroecosystems has been under 
close investigation, both in its native range and in its introduced range. For example, this has included the pursuit of a classical biological control program to introduce Trissolcus japonicus (Hymenoptera: Scelionidae), a parasitoid wasp from the pest's native range in Asia (Talamas et al. 2013; Yang et al. 2009), into the United States. There are also 14 other species of parasitic Hymenoptera that attack the egg stage, as well as predators in the families Anthocoridae (Insecta: Hemiptera), Asilidae (Insecta: Diptera), Cantharidae (Insecta: Coleoptera), Pentatomidae (Insecta: Heimptera), Reduviidae (Insecta: Hemiptera), and Thomisidae (Arachnida: Araneae) that attack various life stages (reviewed in Lee 2015; Lee et al. 2013; Rice et al. 2014). Prior work has examined egg predators, and found that late instar Chrysoperla carnea (Stephens) (Neuroptera: Chrysopidae) were particularly good at consuming H. halys eggs (Abram et al. 2015). In a survey of field-collected predators, it was found that Carabidae, Tettigoniidae, and Dermaptera most frequently attacked $H$. halys egg masses in laboratory trials (Morrison et al. 2016b). Generally, biological control destroys about 4$20 \%$ of $H$. halys egg masses in the field (Ogburn et al. 2016; Cornelius et al. 2016). In terms of adults and nymphs, Jones (2013) found that the wheel bug, Arilus cristatus (Hemiptera: Reduviidae), was one of the most efficient predators of $H$. halys in ornamental settings (Jones 2013). Indeed, most of what we know about the natural enemies of $H$. halys comes from agroecosystems and natural hosts in the landscape during the growing season.

While the predation of active $H$. halys in agroecosystems has been a main focus of prior investigations, the natural enemies at overwintering sites of $H$. halys have never been studied, particularly those commonly found in and around anthropogenic structures. This may be an especially vulnerable time for $H$. halys adults, as they must locate an overwintering site by flying, enter the site, reach a safe location by walking without being intercepted by predators, and remain for an extended period. Over 26,000 H. halys can be found in a single home during the overwintering period in the mid-Atlantic United States (Inkley 2012). In the spring, adult $H$. halys must then exit the overwintering site in order to successfully forage and mate (Lee et al. 2013). Web-building spiders likely represent one of the most severe obstacles to the successful location and utilization of an anthropogenic structure for an overwintering site by $H$. halys, yet represents a completely unknown quantity in the seasonal mortality of the pest.

There has been an increasing appreciation for the role that spiders play in structuring the biotic community in many habitats (Wise et al. 1999), especially considering their role as generalist predators (Riechert and Lockley 1984) and associated trophic cascades produced by non-consumptive effects (e.g. Rypstra and Buddle 2013). In the large coordinated efforts to manage $H$. halys in the United States, spiders have been an understudied predator, both in agroecosystems and in homes. However, a prior study has found that jumping spiders (Salticidae) may be a source of missing H. halys egg masses in large sentinel egg mass deployments (Morrison et al. 2016b). While jumping spiders typically do not build webs, they implicate Araneae as being a possible source of mortality for $H$. halys in the field. The aims of the current study were to evaluate 1) whether webs commonly found in the home and yard can successfully ensnare $H$. halys, 2) whether entrapment resulted in consumption by spiders inhabiting the webs and if this varies over the period that an adult is in a web, and 3) how commonly $H$. halys becomes entangled in webs in homes under natural conditions. 


\section{Materials and Methods}

\section{Study Sites}

The experiments were conducted at three field sites located in West Virginia and Maryland, United States. The sites were at two private residences, including one in Charles Town, WV $\left(39^{\circ} 16^{\prime} 55.99^{\prime \prime} \mathrm{N}, 77^{\circ} 51^{\prime} 17.00^{\prime \prime} \mathrm{W}\right)$ and another in Knoxville, MD $\left(39^{\circ} 20^{\prime} 3.77^{\prime \prime} \mathrm{N}, 77^{\circ} 39^{\prime} 43.81^{\prime \prime} \mathrm{W}\right)$, while the last one was at a research facility, the

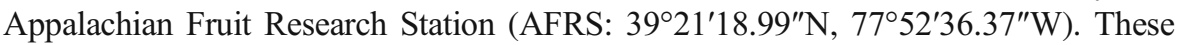
sites were located in severely affected areas of $H$. halys infestation in the United States (www.stopbmsb.org; Inkley 2012), and were thus likely representative of patterns in the invaded range under moderate and high population pressure.

\section{Insects for Experiments}

Halyomorpha halys used in the experiments were obtained from the local landscape concurrently as the season progressed. More specifically, adult $H$. halys were collected and maintained one of two ways. For spring testing (Apr - Jun 2015), adult $H$. halys from known overwintering sites were collected, and kept in a cool, dark location in an unheated shed at AFRS, and those that started becoming active were used. Sites of collection included: Pleasant Valley Elementary School in Knoxville, MD $\left(39^{\circ} 21^{\prime} 31.76^{\prime \prime} \mathrm{N} ; 7^{\circ} 44^{\prime} 33.08^{\prime \prime} \mathrm{W}\right)$, at a residence on a promontory in Inwood, WV $\left(39^{\circ} 23^{\prime} 30.92^{\prime \prime} \mathrm{N} ; 7^{\circ} 5^{\prime} 9.03^{\prime \prime} \mathrm{W}\right)$ and at another residence in Knoxville, MD $\left(39^{\circ} 22^{\prime} 28.42^{\prime \prime} \mathrm{N} ; 77^{\circ} 40^{\prime} 53.59^{\prime \prime} \mathrm{W}\right)$. Adults were collected in overwintering shelters that have been described previously (Bergh et al. 2017; Morrison et al. 2016c). Prior to testing, adults were given a $14 \mathrm{~d}$ period in warmer $(24+0.1 \mathrm{C})$, longer photoperiod conditions $(16: 8 \mathrm{~L}: \mathrm{D})$ to reach an active foraging state and supplied with a combination of water, sundried tomatoes, sunflower seeds, and organic carrots (purchased locally) ad libitum. These adults were of the same generation and presumably same physiological state of individuals that were naturally dispersing from overwintering structures during this period, suggesting that their behavior in experiments should be representative of wild populations.

During the late summer and fall (late-Aug to mid-Oct 2015), adults were collected from the field and from structures that they were preparing to enter for overwintering. Sites for collecting these individuals included: AFRS, an organic farm in Inwood, WV (39²3'41.90"N, 78 4'39.00"W), Pleasant Valley Elementary School, and the residence in Charles Town, WV. These adults were placed in semifield cages under ambient light and temperature cues until used for experiments. The cages consisted of fine mesh netting $(1.83 \times 3.66 \times 1.83 \mathrm{~m}, \mathrm{~L}: \mathrm{H}: \mathrm{W})$ affixed to a wooden palette and located at AFRS. Adults were supplied with potted and fruiting tomatoes (Solanum lycopersicum L.), amaranth (Amaranthus sp.), bell pepper (Capsicum annuum L.), okra (Abelmoschus esculentus Moench) and summer squash (Cucurbita pepo L.). The potted plants were watered daily. Once again, these adults were physiologically and behaviorally similar to ambient populations that were naturally starting to seek out overwintering sites. For all experiments, only robust and healthy adults with all limbs intact were used, with equal representation between males and females. 


\section{Evaluating Spider Capacity for $\boldsymbol{H}$. halys Predation}

Web-building spiders on the interior, exterior, and surrounding buildings were systematically sought out and tested for their ability to entangle, subdue, and consume $H$. halys. All of the trials were performed during periods when $H$. halys was most vulnerable to predation by spiders, namely during the spring emergence period (April Jun 2015) and the fall overwintering period (late Aug - mid-Oct). In each trial, we carefully placed a single adult $H$. halys using forceps near the center of a web that contained at least one active spider. The following details were subsequently recorded for a 5-min observation period: whether the adult $H$. halys escaped, the behavior of the spider, and whether the spider fed on the adult. This was done for a 5 min interval at 0 , 1,2 , and $24 \mathrm{~h}$ after introducing the adult $H$. halys into the web. The behaviors of spiders included: feeding, avoidance, and handling prey (for definitions see Table 1). The time spent exhibiting each behavior was recorded using a stopwatch. In addition, for each trial, the general architecture or shape of the web was noted to understand whether that influenced the ability of $H$. halys to escape. The web was classified as a cob web, orb web, or funnel web (modified from definitions in Blackledge et al. 2009). The location of the web was also recorded (interior building, exterior building, or surrounding landscape). A trial was considered concluded when either the $H$. halys adult escaped from the web, a spider was finished feeding on $H$. halys, or the $24 \mathrm{~h}$ study period had elapsed. At the conclusion of the trial, the spider was assigned a voucher number, preserved in $75 \%(v / v)$ ethanol, and retained for later identification. During identification, each spider was also assigned a size class as follows based on the combined length of the abdomen and cephalothorax: small $(<4 \mathrm{~mm})$, medium $(4-7 \mathrm{~mm})$, or large $(>7 \mathrm{~mm})$. A total of 106 spiders were tested, with 48 located on the exterior of buildings, 40 inside buildings, and 18 in the landscape. The spiders were identified to family using Cushing and Ubick (2009). At the conclusion of the study, the vouchers were deposited in the insect collection at USDA-ARS AFRS.

\section{Evaluating Natural Spider Predation of $\boldsymbol{H}$. halys Indoors and Outdoors}

In order to evaluate the background spider predation rate of $H$. halys indoors, four buildings were surveyed for the remains of adults in webs. This involved systematically searching every room at the site in Charles Town, WV and searching 84\%, 100\%, and

Table 1 Verbal definitions of observed behaviors exhibted by spiders in webs where adult $H$. halys have been introduced

\begin{tabular}{ll}
\hline $\begin{array}{l}\text { Behavior } \\
\text { Feeding }\end{array}$ & $\begin{array}{l}\text { Definition } \\
\text { Inserting chelicerae into any part of } H \text {. halys adult }\end{array}$ \\
Avoidance & $\begin{array}{c}\text { Either } 1 \text { ) dropping down from web on a guide strand and waiting until } \\
\text { disturbance subsides to return, or } 2 \text { ) abandoning web altogether }\end{array}$ \\
Handling Prey & $\begin{array}{c}\text { Direct interaction with adult } H \text {. halys through physical contact other than } \\
\text { feeding; or production of more strands of webbing, and attaching them } \\
\text { as needed to keep adult } H \text {. halys from escaping }\end{array}$ \\
Motionless & Spider does not move after introduction of $H$. halys adult.
\end{tabular}


$100 \%$ of the rooms in three separate buildings at AFRS. In total, 161.4 sq. $\mathrm{m}^{2}$ were searched in the former, and $3130.7 \mathrm{~m}^{2}$ in the latter. For each web, the number of $H$. halys corpses were counted over a month from 16 Sep to 17 Oct 2015. The percent of webs containing $H$. halys remains, and the average number of $H$. halys per web was calculated. As webs were counted, they were removed to avoid any risk of duplication in counts. Each space in the building was only counted a single time.

In addition, to evaluate the background spider predation rate outdoors, a large common boxwood (Buxus sempervirens L.) landscape plant was surveyed at the home in Charles Town, WV and at AFRS on 31 Dec 2015. The count was prior to the first snowfall for the season, so as not to compromise any web remnants. The survey involved systematically searching every web found in the plant, and counting the number of $H$. halys adults (live or dead) in each web. A total volume of $16.3 \mathrm{~m}^{3}$ was searched in Charles Town, and $20.7 \mathrm{~m}^{3}$ in AFRS.

\section{Statistical Analysis}

Two generalized linear models were constructed to perform logistic regression based on a quasibinomial distribution using the binary response of either entanglement (escaped/not escaped), and consumption (eaten/not eaten) for H. halys introduced into webs. Only adults that escaped within the first two time intervals $(0-1 \mathrm{~h})$ were considered as the response variable for entanglement, because no adults escaped in subsequent intervals. The occurrence of predation at any time point in the 24-h sampling period was used as the response for the second model. A predation event was recorded if the chelicerae of a spider were inserted into the cuticle of an $H$. halys adult. Each model contained the location of the web (exterior building, interior building, or landscape), the size of the spider (small, medium, large), spider family, and site as explanatory variables. Site was run as a fixed factor because there were less than the four groups, which is the cutoff for recommendation as a random variable. The web architecture was not used formally in the analysis as web design is phylogenetically conserved among spider taxa (e.g. Blackledge et al. 2009), but these observations are noted in Supplemental Fig. 1. To test for significance in the models, likelihood ratio tests were performed based on a chi-squared distribution because overdispersion was not an issue with either model (Bolker et al. 2008). Pairwise comparisons were performed with chi-squared tests. All tests were carried out using R Statistical Software v.3.2.2 (R Core Development Team 2015) with $\alpha=0.05$ unless otherwise noted.

To understand whether the duration of commonly found behaviors vary by spider taxon after the introduction of $H$. halys into a web, we used a multivariate ANOVA (MANOVA). In particular, we used the feeding time, handling time, avoidance time, and time spent motionless as the response variables. As explanatory variables, we used the spider family and site. Again, site was used as a fixed variable because there were not enough groupings for it to be employed as a random variable. Wilk's approximate $F$-statistic was calculated from the MANOVA. Residuals were inspected for assumptions of normality and homoscedacity, which were not fulfilled. As a result, the data were log-transformed, after which the assumptions were met. Upon a significant result from the overall MANOVA, sequential univariate ANOVAs were performed to understand where differences in the duration of behaviors occurred. Finally, if an ANOVA 
was significant, then pairwise comparisons were performed with Tukey's HSD to understand differences among spider families.

Non-metric multi-dimensional scaling was used to visualize whether there were distinct functional group differences (e.g. Anderson 1997) between the families of spiders that did or did not consume $H$. halys adults at each site. Nonparametric BrayCurtis dissimilarities were calculated, on a pairwise basis, between the set of families that was found either consuming $H$. halys or not; this was based on the family-level mean abundance located at the three sites in the study. The best ordination (e.g. one with the lowest stress value) of 35 attempts was used as the final ordination. To assess the significance of the ordination, an analysis of similarity (ANOSIM) was performed using presence or absence of feeding on $H$. halys as an explanatory variable in order to test whether there were two distinct functional groups. A total of $N=10,000$ permutations were performed to calculate a $P$-value, with $\alpha=0.05$.

\section{Results}

\section{Evaluating Spider Capacity for $\boldsymbol{H}$. halys Predation}

The overall logistic model for $H$. halys introduced into webs that were consumed $\left(\chi^{2}=43.3, \mathrm{df}=12, P<0.0001\right)$, as well as the number that escaped $\left(\chi^{2}=44.1, \mathrm{df}=12\right.$, $P<0.0001)$, were significant. There were significant differences in the percentage of $H$. halys adults consumed among spider families $\left(\chi^{2}=18.4\right.$, $\mathrm{df}=6, P<0.01$, Fig. 1a), as well as the number of adults that escaped $\left(\chi^{2}=13.8, \mathrm{df}=6, P<0.05\right.$, Fig. 1b). Adult $H$. halys were most frequently consumed by Agelenidae, Pholcidae, and Theridiidae, while they were least likely to be consumed by and most likely to escape when in the web of a spider belonging to Tetragnathidae, Araneidae, and Uloboridae (Fig. 1b). In addition, there were significant differences in the likelihood that $H$. halys was consumed $\left(\chi^{2}=8.39\right.$, df $=2, P<0.05$, Fig. $\left.2 \mathrm{a}\right)$ or escaped $\left(\chi^{2}=13.3\right.$, df $=6, P<0.01$, Fig. 2b) among spiders of different sizes. In particular, large spiders were 2.5 times more likely to consume $H$. halys adults than small spiders. Moreover, $H$. halys placed in the webs of small spiders were 6.6 times more likely to escape.

The location of a web (e.g. interior building, exterior building, or landscape) did not significantly affect the probability that $H$. halys adults were either consumed $\left(\chi^{2}=2.13\right.$, $\mathrm{df}=2, P=0.34)$ or escaped $\left(\chi^{2}=2.80, \mathrm{df}=2, P=0.27\right)$. Moreover, the site at which spiders were tested did not significantly affect whether adults were consumed $\left(\chi^{2}=2.31, \mathrm{df}=2, P=0.31\right)$ or whether they escaped $\left(\chi^{2}=4.03, \mathrm{df}=2, P=0.13\right)$.

The overall model explaining the time spent performing activities by spiders in webs where $H$. halys adults were introduced was significant, with spider family influencing how long a behavior was performed (MANOVA: Wilk's $F_{20,302.8}=8.23, P<0.0001$; Fig. 3). However, spider families did not differ in the time spent performing behaviors between sampling sites (MANOVA: Wilk's $F_{8,182}=1.09, P=0.359$ ). In addition, spider families did not differ in the time spent moitionless (ANOVA: $F_{5,94}=0.985$, $P=0.431$ ) or by site (ANOVA: $F_{2,94}=0.964, P=0.385$ ). However, the spider families did differ in their time spent feeding (ANOVA: $F_{5,94}=12.7, P<0.0001$ ), though this did not vary by site $\left(F_{2,94}=0.033, P=0.968\right)$. In particular, Theridiidae, Agelenidae, and Pholcidae spent the longest time feeding on adult $H$. halys after introduction to the 

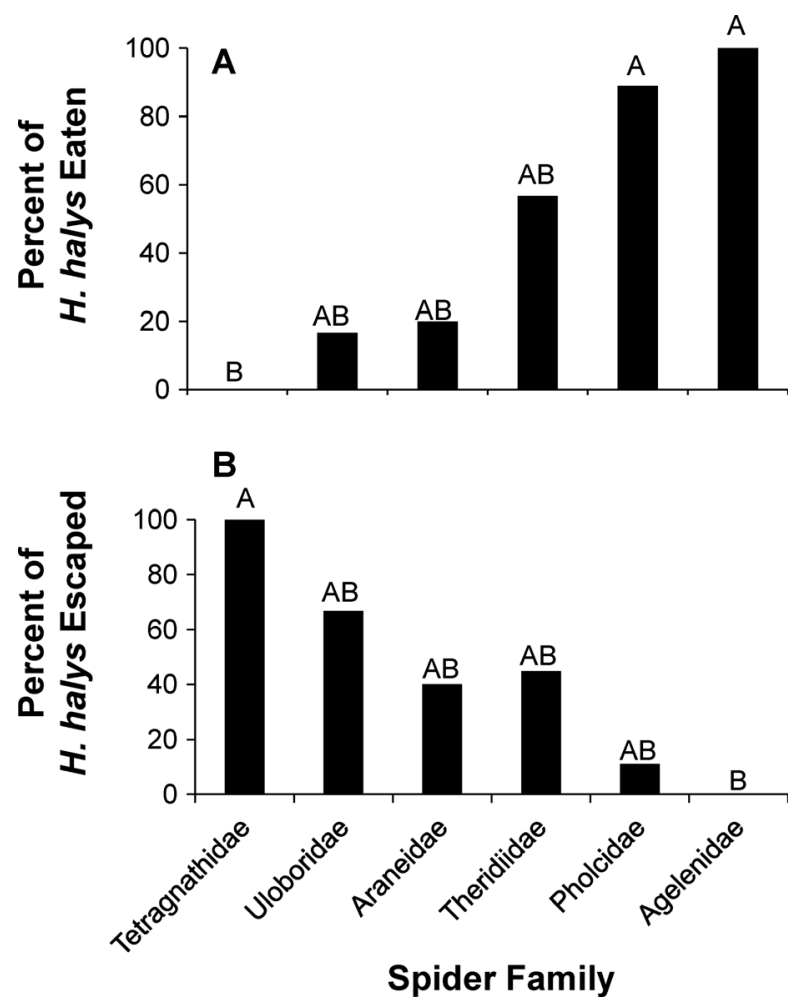

Fig. 1 The effect that spider family has on the (a) percent of adults eaten, and (b) percent of adults escaped. Pairwise comparisons were made with a chi-squared test (Bonferonni correction, $\alpha=0.0056$ ), and bars that share letters are not significantly different from each other

web (Fig. 3a, Tukey's HSD). Moreover, the spider families also differed in the time they spent handling prey (ANOVA: $F_{5,94}=12.5, P<0.0001$ ), though this did not vary by site $\left(F_{2,94}=1.60, P=0.207\right)$. For example, the same three families that spent the most time feeding also spent the most time handling prey: Theridiidae, Agelenidae, and Pholcidae (Fig. 3b, Tukey's HSD). Similarly, the spider families avoided H. halys for differing amounts of time (ANOVA: $F_{5,94}=12.1, P<0.0001$ ), but this pattern was not different by site $\left(F_{2,94}=0.514, P=0.600\right)$. The least avoidant spiders belonged to Uloboridae, Theridiidae, and Agelenidae (Fig. 3c, Tukey's HSD).

There were a total of 7 families found during sampling in structures and landscape, with by far the most common family being Theridiidae (Fig. 4). Theridiidae was more commonly found by 8 and 10 times compared to the next most abundant families, Pholcidae and Araneidae, respectively. The two least commonly found families were Agelenidae and Uloboridae. There were two distinct functional groups of spiders: one that contained a set of families, which fed on H. halys, with another set of spider families that did not (ANOSIM: $R=0.22, P<0.05$; Fig. 5). In particular, individuals belonging to Theridiidae, Pholcidae, and Agelenidae together composed a greater proportion $(98 \%)$ of the community of spiders that used $H$. halys as a prey source compared with those that did not $(64 \%)$. 

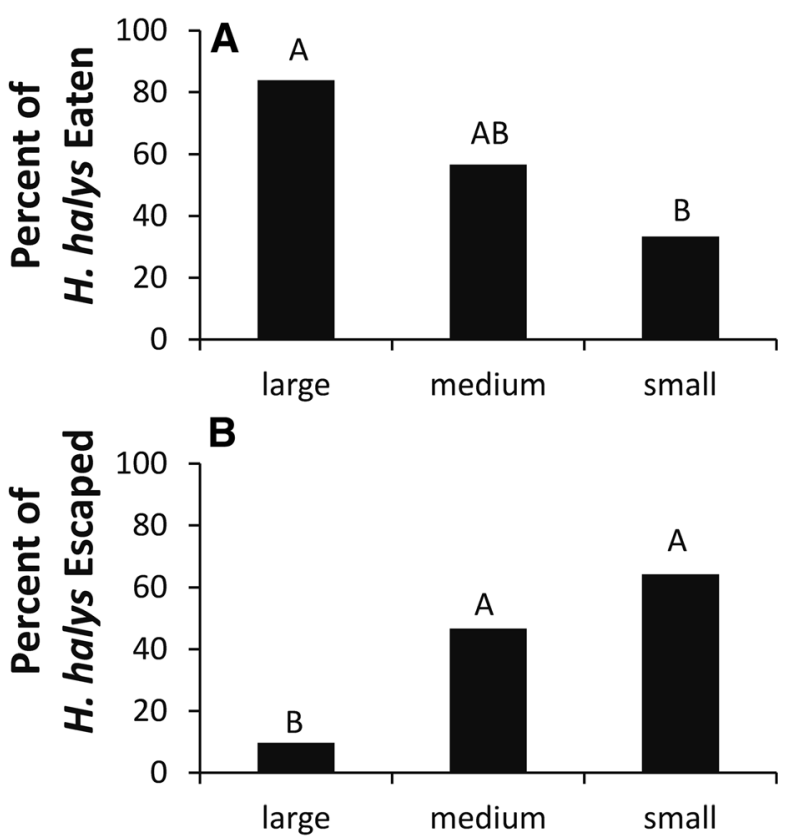

Spider Body Size

Fig. 2 The effect of spider morphology on introduced $H$. halys in webs on (a) the percent of adults eaten, and (b) the percent of adults escaped. Pairwise comparisons with chi-squared test (Bonferonni correction, $\alpha=0.0056$ ), and bars that share letters are not significantly different from each other

\section{Evaluating Natural Spider Predation of $\boldsymbol{H}$. halys}

In total, 246 webs were surveyed on the inside of buildings and on the exterior structure, with a total of $37 \mathrm{H}$. halys adults found. There was an average of $0.31 \pm 0.07$ adult $H$. halys per web. On the interior, $13.2 \%$ of webs contained $H$. halys, while on the exterior of buildings, about $26.5 \%$ of webs contained a dead $H$. halys. At the residence in Charles Town, $17.7 \%$ of webs contained $H$. halys adults, while $14.1 \%$ had adults at AFRS.

Overall in the landscape, 241 webs were surveyed with 49 of them containing $H$. halys adults. There was an average of $0.20 \pm 0.03 H$. halys adults per web. A total of $20 \%$ of webs contained adults at AFRS in the landscape, while $20.8 \%$ contained adults at the landscape plant of the residence in Charles Town.

\section{Discussion}

This is the first study to examine the natural enemies found at overwintering sites for $H$. halys in the early spring and fall, and we have found substantial predation by spiders. Prior work has investigated the natural enemy community of $H$. halys primarily in ornamental and agricultural landscapes during the growing season (e.g. Abram et al. 2015; Abram et al. 2014; Haye et al. 2015a; Jones 2013; Jones et al. 2014; Talamas 

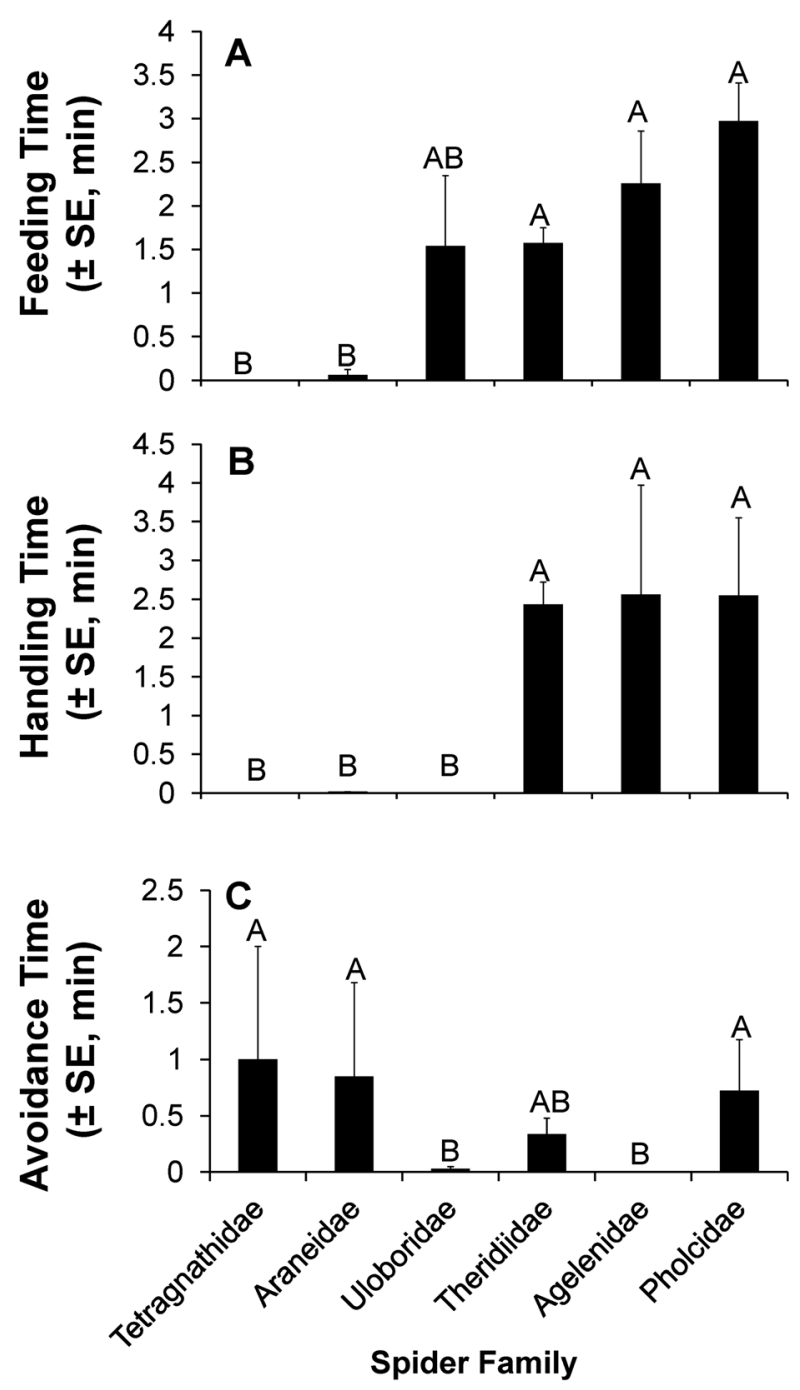

Fig. 3 The mean time spent (a) feeding on, (b) handling, and (c) avoiding H. halys adults after introduction into the web of spiders from various taxa in West Virginia and Maryland, United States. Bars with shared letters are not significantly different from each other (Tukey's HSD, $\alpha=0.05$ )

et al. 2015; Morrison et al. 2016b). In those studies, the most important parasitoids appear to be Trissolcus japonicus, Anastatus spp., and Telenomus spp., while the most important predators are orthopterans, ground beetles, assassin bugs, and earwigs (Jones 2013; Morrison et al. 2016b).

In the current study, we have found that the spider families Agelenidae, Pholcidae, and Theridiidae are most able to ensnare and will most frequently consume $H$. halys adults. However, these families spent the most amount of time handling adult $H$. halys after introduction to the web, suggesting that they have a lower overall predatory efficiency. Our results indicate that the spiders found at the overwintering sites of $H$. halys represent a unique predator community. It seems that the group of spiders at 


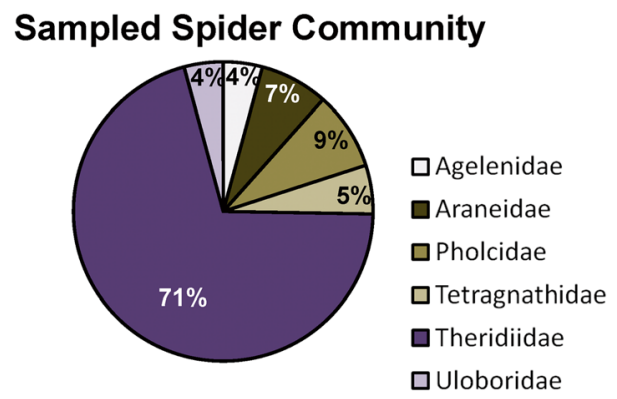

Fig. 4 Community composition of the total spider community where $H$. halys were introduced into webs from three sites spread across West Virginia and Maryland in 2015. Numbers in each slice represent the percentage of total individuals in that family that was tested for predation of $H$. halys out of $n=106$ adults

overwintering sites had lower diversity and a different composition compared to spider communities in apple orchards or grain fields (Marc and Canard 1997; Nyffeler and Sunderland 2003), where $H$. halys is commonly found. Other research has also shown that Salticidae may be potential predators of $H$. halys egg masses in agricultural landscapes (Morrison et al. 2016b), and our findings suggest that other spider families may also contribute to the mortality of $H$. halys in those habitats. While our study did not resolve the spider taxa below family, species-level information may be important in future studies to begin to target specific species in integrated pest management programs for homeowners and growers.

Spiders are an often underappreciated, but significant source for population regulation in many systems (Riechert and Lockley 1984). It appears that in the overwintering sites included here, about $13-20 \%$ of webs contained dead $H$. halys adults. This number will undoubtedly vary depending on the population density of $H$. halys in a specific location, and other landscape factors and structure characteristics such as level of urbanization and color or material of structure (Hancock et al., unpublished). Because the locations used in this study were in the part of the USA that is severely affected by $H$. halys, these numbers are likely near the upper range of biological control by spiders inside and around human dwellings. Nevertheless, this is well below the

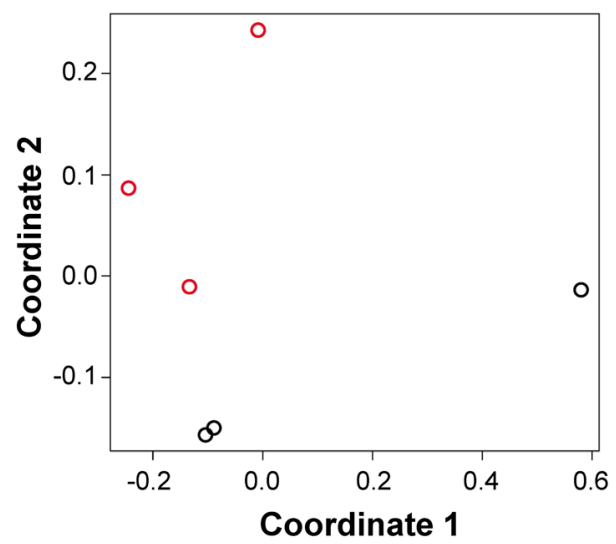

Fig. 5 NMDS ordination based on Bray-Curtis similarities showing the differences in the spider community either consuming H. halys (red) or not (black) at each study site. The ordination stress value $=0.02$ 
level of biological control needed to regulate the $H$. halys population in the study area indicated by the high abundance in the mid-Atlantic US (Leskey et al. 2015a, 2015b). However, our study reveals that spiders seem to be at least a contributing mortality factor for $H$. halys at these overwintering sites.

The main factor for whether a spider consumed a $H$. halys adult seemed to be whether it was ensnared by the web and subdued by the spider. Though not included in the main analysis, spiders with a funnel or cob web architecture seemed most able ensnare H. halys, while orb webs were the least effective (Supplemental Fig. 1). While the claims made from this part of the data are limited, prior research has shown that the ability of orb webs to capture heavy, quickly flying prey depends on the size of the web, the size of the spider, the tension on the web, and the ratio of radii to spiral turns per web, with larger webs, heftier spiders, more tension, and ratios greater than 1 resulting in the greatest ability of an orb web to capture such prey (Craig 1987). In contrast, the orb webs in the current study were reduced, woven by smaller spiders compared to spiders weaving other types of webs in this study, and the orb webs were loosely attached to the substrate (Morrison, pers. Obs.). As a result, these orb webs were less able to cope with the introduction of $H$. halys, which is a heavy insect capable of flying up to $115 \mathrm{~km}$ in a $22 \mathrm{~h}$ period (Lee and Leskey 2015). In addition, whether spiders produce cribellate or woolly silk (e.g. Uloboridae) compared with ecribellate or sticky silk (e.g. Theridiidae) may also impact predation (Rypstra 1982). Other factors that may influence the ability of a web to retain prey include the prey density (Nentwig 1982), and the spider's reaction time (Zschokke and Herberstein 2005), among other factors. Indeed, the spider's behavior and reaction time was a critical factor in making the funnel web spiders (Agelenidae) so effective. These spiders emerged rapidly from their shelter, pursued adult $H$. halys speedily who were slowed down by the web, and dragged them back to their shelter (Morrison, pers. Obs.)

In addition to web type, larger sized spiders seemed most able to subdue $H$. halys adults. This fits with previous research that shows that the predator-prey mass ratio matters in determining predation in spiders (e.g. Craig 1987; Brose et al. 2006; Kalinkat et al. 2011; Michalko and Pekar 2015). Therefore, our results suggest that medium to large spiders with cob or funnel web architecture may be especially effective in ensnaring and subduing adult $H$. halys.

Interestingly, the number of adult $H$. halys eaten is nearly the reciprocal of the number of adults escaped. However, this need not be the case, as an adult $H$. halys may not be able to escape, and the spider may still reject the prey item due to host preference, or because of chemical defenses. As is the case for many pentatomids, $H$. halys possesses a defensive compound, composed primarily of tridecane and E-2decenal (Baldwin et al. 2014). Despite the fact that $H$. halys is equipped with this predator deterrent, feeding by spiders was not lessened, even on those occasions when chemical defenses were emitted (Morrison, pers. Obs.). None of the spiders were deterred, out of the over 100 individuals tested, with individuals often first approaching $H$. halys and then retreating before attempting to handle and subdue the prey. In a study where over 2500 prey insects were tested for feeding by species in four spider families (e.g. Aaraneidae, Linyphiidae, Pholcidae, and Agelenidae), defensive secretions from 30 species of Heteroptera had very low deterrent effect (Nentwig 1983). In that study, $76 \%$ of the Heteroptera were consumed. The explanation given in that study is that the web may act as a tool for detoxification, with pentatomids quickly expelling their 
defensive secretions when caught, and left with emptied defensive glands by the time that the spider finally moves in to subdue the prey. The spider families that spent the most time feeding on $H$. halys in the current study, also spent the least amount of time avoiding introduced adults. Overall, there seems to be at least two functional groups, which was confirmed by the multivariate ordination procedure. One functional group contains spiders with a suite of behaviors (aggressive, mobile, quick), physical traits (medium to large-sized) and abilities (strong, sticky webs) that allows them to successfully exploit $H$. halys as a food source, while a second functional group is likely composed of less aggressive and smaller spiders that weave webs too weak to ensnare $H$. halys successfully. In either case, the defensive secretions of $H$. halys seemed to have little to no deterrent effect on predation by spiders in this study.

Prior authors have already argued for habitat management in agricultural systems to increase spider populations for improved pest control (e.g. Marc et al. 1999). While not as popular among the general populace (Lemelin and Yen 2015), spiders present in anthropogenic structures may help increase the mortality of $H$. halys adults. Our work suggests that if an adult lands in the right web (e.g. a cob or funnel web of a medium- to large-sized spider belonging to Theridiidae, Pholcidae, or Agelenidae) there is a greater than $50 \%$ chance of the individual being eaten. Despite this, it is clear that the current level of spider predation is not sufficient to provide adequate control in anthropogenic structures. Nonetheless, our study highlights the possibility of altering the habitat through some measure to increase the biological control services provided by spiders. While impractical in an anthropogenic setting, the use of habitat management to positively affect the spider community in agroecosystems and natural systems has been well-researched (e.g. Schmidt et al. 2005; Finke and Denno 2002). In particular, increased habitat complexity through cover crops, intercrops, and reduced tillage, as well as reduced use of broad spectrum insecticides has resulted in increased abundance and/or diversity of spiders (Rypstra et al. 1999; Mansour et al. 1983).

We have shown that spiders have the capacity to consume highly mobile $H$. halys adults, and that they in fact do so based on information from surveys of background predation. Future work on natural enemies should elucidate the role that spiders play in providing biological control of $H$. halys in agricultural systems. Finally, further work with the overwintering sites of $H$. halys may shed light on other major predator groups in and around anthropogenic structures that can be of use in reducing $H$. halys populations.

Acknowledgements The authors would like to thank Morgan Douglas and Nate Brandt for their excellent technical assistance in the laboratory and field. This research was funded, in part, by a USDA-NIFA SCRI CAP Grant\#2011-51181-30937.

\section{References}

Abram PK, Gariepy TD, Boivin G, Brodeur J (2014) An invasive stink bug as an evolutionary trap for an indigenous egg parasitoid. Biol Invasions 16:1387-1395

Abram PK, Doyon J, Brodeur J, Gariépy TD, Boivin G (2015) Susceptibility of Halyomorpha halys (hemiptera: Pentatomidae) eggs to different life stages of three generalist predators. Can Entomol 147: 222-226 
Anderson A (1997) Functional groups and patterns of organization in north American ant communities: a comparison with Australia. J Biogeo 24:433-460

Baldwin RL, Zhang A, Fultz SW, Abubeker S, Harris C, Connor EE, Van Hekken DL (2014) Hot topic: Brown marmorated stink bug odor compounds do not transfer into milk by feeding bug-contaminated corn silage to lactating dairy cattle. J Dairy Sci 97:1877-1884

Bergh JC, Morrison III WR, Joseph SV, Leskey TC (2017) Characterizing spring emergence of adult Halyomorpha halys using experimental overwintering shelters and commercial pheromone traps. Entomol Exp Appl. doi:10.1111/eea.12539

Blaauw BR, Polk D, Nielsen AL (2014) IPM-CPR for peaches: incorporating behaviorally-based methods to manage Halyomorpha halys and key pests in peach. Pest Manag Sci 71:1513-1522

Blackledge TA, Scharff N, Coddington JA, Szuts T, Wenzel JW, Hayashi CY, Agnarsson I (2009) Reconstructing web evolution and spider diversification in the molecular era. P Natl Acad Sci USA 106:5229-5234

Bolker BM, Brooks ME, Clark CJ, Geange SW, Poulsen JR, Stevens MHH, White J-SS (2008) Generalized linear mixed models: a practical guide for ecology and evolution. Trends Ecol Evol 24:127-135

Brose U, Jonsson T, Berlow EL, Warren P, Banasek-Richter C et al (2006) Consumer-resource body-size relationships in natural food webs. Ecology 87:2411-2417

Cornelius ML, Dieckhoff C, Hoelmer KA, Olsen RT, Weber DC, Herlihy MV, Talamas EJ, Vinyard BT, Greenstone MH (2016) Biological control of sentinel egg masses of the exotic invasive stink bug Halyomorpha halys (Stål) in mid-Atlantic USA ornamental landscapes. Biol Control 103:11-20

Craig CL (1987) The ecological and evolutionary interdependence between web architecture and web silk spun by orb web weaving spiders. Biol J Linn Soc 30:135-162

Cushing P, Ubick DP (2009) Spiders of North America: an identification manual. The American Arachnological Society, Greenville

Finke DL, Denno RF (2002) Intraguild predation diminished in complex-structured vegetation: implications for prey suppression. Ecology 83:643-652

Fogain R, Graff S (2011) First records of the invasive pest, Halyomorpha halys (hemiptera: Pentatomidae), in Ontario and Quebec. J Ent Soc Ont 142:45-48

Haye T, Fischer S, Zhang J, Gariepy TD (2015a) Can native parasitoids adopt the invasive brown marmorated stink bug, Halyomorpha halys (Heteroptera: Pentatomidae), in Europe? J Pest Sci 88:693-705

Haye T, Gariepy T, Hoelmer K, Rossi J-P, Streito J-C, Tassus X, Desneux N (2015b) Range expansion of the invasive brown marmorated stinkbug, Halyomorpha halys: an increasing threat to field, fruit and vegetable crops worldwide. J Pest Sci 88:665-673

Hoebeke ER, Carter ME (2003) Halyomorpha halys (Stål) (Heteroptera : Pentatomidae): a polyphagous plant pest from Asia newly detected in North America. Proc Ent Soc WA 105:225-237

Inkley DB (2012) Characteristics of home invasion by the brown marmorated stink bug (hemiptera: Pentatomidae). J Entomol Sci 47:125-130

Jones A (2013) Indigenous natural enemies of the invasive brown marmorated stink bug, Halyomorpha halys (hemiptera: Pentatomidae). Department of Entomology, University of Maryland, College Park, Master of Science

Jones AL, Jennings DE, Hooks CRR, Shrewsbury PM (2014) Sentinel eggs underestimate rates of parasitism of the exotic brown marmorated stink bug, Halyomorpha halys. Biol Control 78:61-66

Kalinkat G, Rall BC, Vucic-Pestic O, Brose U (2011) The allometry of prey preferences. PLoS One 6:e25937 Khrimian A, Zhang A, Weber DC, Ho HY, Aldrich JR, Vermillion KE, Siegler MA, Shirali S, Guzman F, Leskey TC (2014) Discovery of the aggregation pheromone of the brown marmorated stink bug (Halyomorpha halys) through the creation of stereoisomeric libraries of 1-bisabolen-3-ols. J Nat Prod 77:1708-1717

Lara J, Pickett C, Ingels C, Haviland DR, Grafton-Cardwell E, Doll D, Bethke J, Faber B, Dara SK, Hoddle M (2016) Biological control program is being developed for brown marmorated stink bug. CA Agric 70:15-23

Lee D-H (2015) Current status of research progress on the biology and management of Halyomorpha halys (hemiptera: Pentatomidae) as an invasive species. Appl Entomol Zool 50:277-290

Lee D-H, Leskey TC (2015) Flight behavior of foraging and overwintering brown marmorated stink bug, Halyomorpha halys (hemiptera: Pentatomidae). B Entomol Res 105:566-573

Lee D-H, Short BD, Joseph SV, Bergh JC, Leskey TC (2013) Review of the biology, ecology, and management of Halyomorpha halys (hemiptera: Pentatomidae) in China, Japan, and the Republic of Korea. Environ Entomol 42:627-641

Lee D-H, Cullum JP, Anderson JL, Daugherty JL, Beckett LM, Leskey TC (2014) Characterization of overwintering sites of the invasive brown marmorated stink bug in natural landscapes using human surveyors and detector canines. PLoS One 9:e91575 
Lemelin RH, Yen A (2015) Human-spider entanglements: understanding and managing the good, the bad, and the venomous. Anthrozoos 28:215-228

Leskey TC, Hamilton GC, Nielsen AL, Polk DF, Rodriguez-Saona C, Bergh JC, Herbert DA, Kuhar TP, Pfeiffer D, Dively GP, Hooks CRR, Raupp MJ, Shrewsbury PM, Krawczyk G, Shearer PW, Whalen J, Koplinka-Loehr C, Myers E, Inkley D, Hoelmer KA, Lee D-H, Wright SE (2012a) Pest status of the brown marmorated stink bug, Halyomorpha halys in the USA. Outlooks on Pest Management 23:218-226

Leskey TC, Wright SE, Short BD, Khrimian A (2012b) Development of behaviorally-based monitoring tools for the brown marmorated stink bug (Heteroptera: Pentatomidae) in commercial tree fruit orchards. J Entomol Sci 47:76-85

Leskey TC, Short BD, Butler BR, Wright SE (2012c) Impact of the invasive brown marmorated stink bug, Halyomorpha halys (Stål), in mid-Atlantic tree fruit orchards in the United States: case studies of commercial management. Psyche 2012:1-14

Leskey TC, Agnello A, Bergh CJ, Dively GP, Hamilton GC, Jentsch P, Khrimian A, Krawczyk G, Kuhar TP, Lee D-H, Morrison WR III, Polk DF, Rodriguez-Saona C, Shearer PW, Short BD, Shrewsbury PM, Walgenbach JF, Weber DC, Welty C, Whalen J, Wiman NG, Zaman F (2015a) Attraction of the invasive Halyomorpha halys (hemiptera: Pentatomidae) to traps baited with semiochemical stimuli across the United States. Environ Entomol 44:746-756

Leskey TC, Khrimian A, Weber DC, Aldrich JR, Short BD, Lee D-H, Morrison WR III (2015b) Behavioral responses of the invasive Halyomorpha halys (Stål) to traps baited with stereoisomeric mixtures of 10,11epoxy-1-bisabolen-3-ol. J Chem Ecol 41:418-429

Mansour F, Richman DB, Whitcomb WH (1983) Spider management in agroecosystems: habitat manipulation. Envrion Manage 7:43-49

Marc P, Canard A (1997) Maintaining spider biodiversity in agroecosystems as a tool in pest control. Agric Ecosyst Environ 62:229-235

Marc P, Canard A, Ysnel F (1999) Spiders (Araneae) useful for pest limitation and bioindication. Agric Ecosyst Environ 74:229-273

Martinson HM, Venugopal PD, Bergmann EJ, Shrewsbury PM, Raupp MJ (2015) Fruit availability influences the seasonal abundance of invasive stink bugs in ornamental tree nurseries. J Pest Sci 88:461-468

Michalko R, Pekar S (2015) The biocontrol potential of Philodromus (Araneae, Philodromidae) spiders for the suppression of pome fruit orchard pests. Biol Control 82:13-20

Morrison WR III, Cullum JP, Leskey TC (2015) Evalulation of trap designs and deployment strategies for capturing Halyomorpha halys (hemiptera: Pentatomidae). J Econ Entomol 108:1683-1692

Morrison WR III, Lee D-H, Short BD, Khrimian A, Leskey TC (2016a) Establishing the behavioral basis for an attract-and-kill strategy to manage the invasive Halyomorpha halys in apple orchards. J Pest Sci 89: 81-96

Morrison WR III, Mathews CR, Leskey TC (2016b) Frequency, efficiency, and physical characteristics of predation by generalist predators of brown marmorated stink bug (hemiptera: Pentatomidae) eggs. Biol Control 97:120-130

Morrison WR III, Poling B, Leskey TC (2016c) The consequences of sublethal exposure to insecticide on the survivorship and mobility of Halyomorpha halys (hemiptera: Pentatomidae). Pest Manag Sci 73:389-396

Nentwig W (1982) Why do only certain insects escape from a spider's web? Oecologia 83:412-417

Nentwig W (1983) The prey of web-building spiders compared with feeding experiments (Araneae: Araneidae, Linyphiidae, Pholcidae, Agelenidae). Oecologia 56:132-139

Nielsen AL, Hamilton GC (2009a) Life history of the invasive species Halyomorpha halys (hemiptera: Pentatomidae) in northeastern United States. Ann Entomol Soc Am 102:608-616

Nielsen AL, Hamilton GC (2009b) Seasonal occurrence and impact of Halyomorpha halys (hemiptera: Pentatomidae) in tree fruit. J Econ Entomol 102:1133-1140

Nielsen AL, Dively G, Pote JM, Zinati G, Mathews C (2016a) Identifying a potential trap crop for a novel insect pest Halyomorpha halys (hemiptera: Pentatomidae), in organic farms. Environ Entomol, in press. doi:10.1093/ee/nvw006

Nielsen AL, Fleischer S, Chen S (2016b) Coupling developmental physiology, photoperiod, and temperature to model phenology and dynamics of an invasive Heteropteran, Halyomorpha halys. Frontiers in Physiology, in press. doi:10.3389/fphys.2016.00165

Nyffeler M, Sunderland KD (2003) Composition, abundance and pest control potential of spider communities in agroecosystems: a comparison of European and US studies

Ogburn EC, Bessin R, Dieckhoff DR, Grieshop M, Hoelmer KA, Mathews C, Moore J, Nielsen AL, Poley K, Pote JM, Rogers M, Welty C, Walgenbach JF (2016) Natural enemy impact on eggs of the invasive brown 
marmorated stink bug, Halyomorpha halys (Stål) (hemiptera: Pentatomidae), in organic agroecosystems: a regional assessment. Biol Control 101:39-51

Owens DR, Herbert DA, Dively GP, Reisig DD, Kuhar TP (2013) Does feeding by Halyomorpha halys (hemiptera: Pentatomidae) reduce soybean seed quality and yield? J Econ Entomol 106:1317-1323

R Core Development Team (2015) R: A language and environment for statistical computing. R Foundation for Staistical Computing, http://www.R-project.org/, Vienna, Austria

Rice KB, Bergh CJ, Bergmann EJ, Biddinger DJ, Dieckhoff C, Dively G, Fraser H, Gariepy T, Hamilton G, Haye T, Herbert A, Hoelmer K, Hooks CR, Jones A, Krawczyk G, Kuhar T, Martinson H, Mitchell W, Nielsen AL, Pfeiffer DG, Raupp MJ, Rodriguez-Saona C, Shearer P, Shrewsbury P, Venugopal PD, Whalen J, Wiman NG, Leskey TC, Tooker JF (2014) Biology, ecology, and management of brown marmorated stink bug (hemiptera: Pentatomidae). Journal of Integrated Pest Management 5:1-13

Riechert SE, Lockley T (1984) Spiders as biological control agents. Annu Rev Entomol 29:299-320

Rypstra AL (1982) Building a better insect trap; an experimental investigation of prey capture in a variety of spider webs. Oecologia 52:31-36

Rypstra AL, Buddle CM (2013) Spider silk reduces insect herbivory. Biol Letters 9:20120948

Rypstra AL, Carter PE, Balfour RA, Marshall SD (1999) Architectural features of agricultural habitats and their impact on the spider inhabitants. J Arachnol 27:371-377

Schmidt MH, Roschewitz I, Thies C, Tscharntke T (2005) Differential effects of landscape and management on diversity and density of ground-dwelling farmland spiders. J Appl Ecol 42:281-287

Soergel DC, Ostiguy N, Fleischer SJ, Troyer RR, Rajotte EG, Krawczyk G (2015) Sunflower as a potential trap crop of Halyomorpha halys (hemiptera: Pentatomidae) in pepper fields. Environ Entomol 44:1581-1589

Talamas E, Buffington M, Hoelmer K (2013) New synonymy of Trissolcus halyomorphae Yang. J Hymenopt Res 33:113-117

Talamas EJ, Herlihly MV, Dieckhoff C, Hoelmer K, Buffington M, Bon M-C, Weber DC (2015) Trissolcus japonicus (Ashmead) (hymenoptera: Scelionidae) emerges in North America. J Hymenopt Res 43:119-128

Weber DC, Leskey TC, Walsh GC, Khrimian A (2014) Synergy of aggregation pheromone with methyl (E,E, Z)-2,4,6-decatrienoate in attraction of Halyomorpha halys (Hemiptera: Pentatomidae). J Econ Entomol 107:1061-1068

Wermelinger B, Wyniger D, Forster B (2008) First records of an invasive bug in Europe: Halyomorpha halys stal (Heteroptera: Pentatomidae), a new pest on woody ornamentals and fruit trees? Mit Sch Entomol Ges 81:1-8

Wiman NG, Parker JE, Rodriguez-Saona C, Walton VM (2015) Characterizing damage of brown marmorated stink bug (hemiptera: Pentatomidae) in blueberries. J Econ Entomol 108:1156-1163

Wise DH, Snyder WE, Tuntibunpakul P, Halaj J (1999) Spiders in decomposition food webs of agroecosystems: theory and evidence. J Arachnol 27:363-370

Yang Z-Q, Yao Y-X, Qiu L-F, Li Z-X (2009) A new species of Trissolcus (hymenoptera: Scelionidae) parasitizing eggs of Halyomorpha halys (Heteroptera: Pentatomidae) in China with comments on its biology. Ann Entomol Soc Am 102:39-47

Zhu G, Bu W, Gao Y, Liu G (2012) Potential geographic distribution of brown marmorated stink bug invasion (Halyomorpha halys). PLoS One 7:e31246

Zschokke S, Herberstein ME (2005) Laboratory methods for maintaining and studying web-building spiders. J Arachnol 33:205-213 